4. The Carter Observatory Astronomical Handbook for New Zealand observers is available from Carter Observatory, P.O. Box 2909, Wellington 1, New Zealand.

5. Jeffers, H.M. et al. (1963). Index Catalogue of Visual Double Stars, 1961.0. Lick Observatory.

\title{
Discussion
}

P.W. Hill: Professional astronomers are extremely grateful for the work of New Zealand amateurs, particularly in the field of variable stars.

\section{SYDNEY OBSERVATORY GOES PUBLIC}

\section{N.R. Lomb and T. Wilson}

Sydney Observatory, PO Box K346, Haymarket 2000, Australia

\section{Sydney Observatory}

In 1982, after a 124-year history of research, Sydney Observatory became a branch of a large local museum, the Museum of Applied Arts and Sciences. A fouryear, million-dollar project was undertaken to restore the building and its grounds to their nineteenth century appearance. The services needed for a modern museum were also added. One of the larger areas became a modern lecture theater seating up to fifty people, with back projection video, film and slide projectors.

Exhibition space within the building is limited to eight rooms of approximately $200 \mathrm{~m}^{2}$ total area. To overcome this lack of space, a proposal has been made for an extension to the rear of the building. An underground 100-seat planetarium is included in the proposal. There is a great need for this as there is no planetarium currently in Sydney.

\section{Halley's Comet Exhibition}

From January to May 1986 an exhibition on Halley's Comet was put on in a part of the Observatory building. In the first and main display area, visitors found themselves in a spaceship. This spaceship had spot lighting, synthesized music and a fluorescent background of stars and galaxies. Exhibits included:

- the written record from 1835 of the first (European) sighting of Halley's Comet in Australia and the telescope with which the observation was made;

- the telescope with which the Great Comet of 1861 was discovered; 
- plates of the comet made at the Observatory in 1910 , together with modern contrast enhanced prints from the plates;

- computers, interactive exhibits, and a 10-minute audiovisual program.

There were 47,000 visitors to the exhibition during the five months.

\section{The 29-cm Telescope}

Evening telescope viewings are held for the public on six nights a week. The remaining night is used for adult education courses in astronomy and an amateur astronomy group. Until recently the main telescope used for the public viewings was the historic $29-\mathrm{cm}$ refractor. This was obtained by the Observatory to observe the 1874 transit of Venus. Its main limitation is that objects shown with it are limited to those that can be seen with the naked eye in a highly light-polluted sky. The newly installed computer-controlled $\mathrm{C}$-14 telescope does not have the same problem and it is envisaged that with narrow-band filters and an image intensifier, regions of faint nebulosity will be visible.

\section{Repeating Circle}

The plans for the permanent exhibition include not only interactive exhibits, but also displays of antique astronomical instruments. The Museum has a large collection of nineteenth century items, most of which came with the Observatory. Possibly, the most important items are a collection of instruments from the first permanent observatory in Australia. This observatory was set up in 1821 at Parramatta, which is now an outer suburb of Sydney. Included in the collection are a Breguet regulator clock, a refracting telescope, a transit telescope and the repeating circle.

\section{Hands-On Astronomy}

The current exhibition at the Observatory is made up of interactive exhibits. They are prototypes that are being tried out for possible use in the planned permanent exhibition. Some of these are discussed below.

a) Weights on Other Worlds

This exhibit demonstrates the different pull of gravity on various solar system bodies: the sun, the Earth, the moon and Jupiter. Appropriate amounts of lead shot have been placed inside the empty cartons.

\section{b) Colored Pictures}

In this demonstration of image processing, a picture of the Horsehead Nebula is color coded according to intensity. Then, using a TV camera, the same process is carried out on real-time images of the visitor. The exhibit is based on an IBM PC and an image-processing card. 
Other computer exhibits on display are based on Amiga computers. One interactive program tells the visitor about the solar system; with another the visitor can build a telescope on the screen and test it out.

c) Look for Galaxies

In this exhibit, visitors look with a magnifying glass at a back-lit film negative from the UK Schmidt Telescope. The photograph is of the Fornax Cluster and so contains a variety of types of galaxies.

d) Star Pictures

This is a constellation guessing game. Visitors can choose from four different constellations and try to guess the constellation before pushing the answer button. Optical fibers are used to display the star patterns. A similarly built exhibit demonstrates stellar scintillation.

e) Supernova

A zoetrope (an optical device in which figures on the inside of a revolving cylinder are viewed through slits in its circumference and appear like a single animated figure) is used to show the implosion of the core and the expansion of the outer layer in a supernova. Even more ambitiously, another zoetrope shows the "big bang" and the expansion of the universe.

f) Astronomical Picture Show

The videodisk based exhibit shows a pre-selected series of astronomical images. A title is displayed with each image. This visitor can choose to obtain extra information. 